\title{
CONDUCTIVE ADHESIVES FOR SOLID TANTALUM CAPACITORS PROCESS AND ESR OPTIMISATION BY MATERIAL SELECTION*
}

\author{
G. DREEZEN $\dagger$, E. DECKX and G. LUYCKX \\ Emerson \& Cuming, ICI Belgium NV, Nijverheidsstraat 7, B-2260 Westerlo, Belgium
}

(Received December 2001)

Keywords: Tantalum capacitors, conductive adhesives, Equivalent Series Resistance

\section{INTRODUCTION}

With the dramatic growth in electronic circuitry applications, more demands are being placed on those systems' integrity and reliability. More circuits require use of higher frequencies and smaller space to miniaturise products. The next generation microprocessors require lower voltages and increased supply currents. Over the past 3,5 years, microprocessor current has increased 5 times and equivalent series resistance (ESR) requirements have dropped by a factor 7 . Therefore, capacitors must have high capacitance and low ESR [1]. Tantalum capacitor manufacturers have been developing novel technologies such as new anode design \& process optimisation in order to achieve the lowest possible ESR [2-7]. Conductive silver adhesives used for bonding the tantalum anodes onto the leadframe have an impact on both the electrical and mechanical performance. As a supplier of such adhesives, Emerson \& Cuming conducted a research program in order to identify and develop silver adhesives combining a very high throughput with excellent electrical and mechanical performance.

This paper investigates the effect of different adhesives combined with different leadframe metallisations on the ESR and the mechanical strength. The effect of the cure schedule has also been investigated. It is concluded that the selection of a conductive silver adhesive depends on the metallisation of the leadframe and the preferred cure method.

\footnotetext{
* An earlier version of this paper was published in the Proceedings of the 15th Annual European Passive Components Conference (CARTS-EUROPE 2001), 15-19 October 2001, pp. 193-196

$\dagger$ Corresponding author. Tel.: + 32145756 11; Fax: +32 145855 30; E-mail: gunther.dreezen@nstarch.com
} 


\section{BACKGROUND}

A tantalum capacitor design has been discussed in detail in a previous publication [8]. From this study it was concluded that both the graphite and silver coating used to connect all the $\mathrm{MnO}_{2}$ to the external cathode can have a strong impact on the ESR performance of the tantalum capacitor. Material selection and process optimisation recommendations have been proposed [8].

After dipping and curing of the graphite and silver coating the cathode terminals are joined to the cathode leadframes using a silver loaded conductive adhesive. The anode wires are welded to the anode leadframe. Finally, the element is moulded in an epoxy resin case to ensure pick and placeability and tight control over the component dimensions.

The electrically conductive adhesives used are typically epoxy-based containing 70 to $80 \%$ by weight of silver in order to achieve electrical conductivity after cure. These adhesives are available as two-component, premixed and frozen systems or real one-component materials and can be applied by pin transfer, dispensing or printing. Both (slow) oven cure or (fast) snap cure processes can be used depending on the adhesive type. Leadframe metallisations typically used are silver, tin or tin/lead.

The resistance losses occurring in a capacitor are expressed in the equivalent series resistance (ESR) and is one of the primary parameters characterising these products [9]. The ESR decreases with increasing frequency. At high frequencies, commonly used in most circuit applications, contributions to the ESR from the tantalum anode and the $\mathrm{Ta}_{2} \mathrm{O}_{5}$ dielectric are negligible. Tantalum capacitor manufacturers ascribe the bulk of the ESR contribution to the $\mathrm{MnO}_{2}$ layer $[2,10]$. The $\mathrm{MnO}_{2}$ contribution is related to both resistivity and geometric factors, depending strongly on manufacturing procedures. Much effort is expended by capacitor manufacturers to keep the resistance low and repeatable.

The ESR performance of electrically conductive adhesives is not often discussed in literature. In this paper the performance of different chemistries is considered. The ESR numbers on semi-finished capacitors combined with different leadframe metallisations are compared. The effect of the curing conditions on the ESR is studied as well. Secondly, the mechanical strength of the silver adhesives as a function of the leadframe metallisation is studied and these mechanical data are compared with the ESR data. Finally, recommendations for conductive silver adhesive selections are made.

\section{EXPERIMENTAL SETUP}

\section{Capacitors}

Semi-finished B and E-case capacitors were used. The capacitors were received with graphite coating and dipped with a silver coating and cured in the lab. E-case capacitors were used to evaluate the ESR performance whereas the study of adhesive strength was performed using B-case capacitors.

\section{Conductive Silver Adhesives}

Seven silver adhesives have been selected for this study. Some were not typical epoxy chemistries as described in Table I. Two materials were chosen because they can be cured in both oven and snap-cure processes. The cure temperature was, where possible, kept at $150{ }^{\circ} \mathrm{C}$. 
TABLE I Studied Conductive Silver Adhesives (Application Methods: $1=$ Dispensing, 2 = Printing, $3=$ Pin Transfer).

\begin{tabular}{llcl}
\hline Material & Chemistry & Application method & Cure schedule \\
\hline A1 & Epoxy & 1 or 2 & $60 \mathrm{~s} @ 180^{\circ} \mathrm{C}$ \\
& & $30 \min @ 150^{\circ} \mathrm{C}$ \\
A2 & Epoxy & 1 & $45 \min @ 120^{\circ} \mathrm{C}$ \\
& & & $60 \mathrm{~s} @ 1800^{\circ} \mathrm{C}$ \\
A3 & Epoxy & 1 & $30 \min @ 150^{\circ} \mathrm{C}$ \\
A4 & Epoxy & 1 or 3 & $30 \min @ 120^{\circ} \mathrm{C}$ \\
A5 & Epoxy Silicone & 1 & $150^{\circ} \mathrm{C}$ \\
A6 & Silicone & 1 & $30 \mathrm{~min} @ 150^{\circ} \mathrm{C}$ \\
A7 & Epoxy & 1 & $1 \mathrm{~h} @ 150^{\circ} \mathrm{C}$ \\
& & & $1 \mathrm{~h} @ 180^{\circ} \mathrm{C}$ \\
\hline
\end{tabular}

For some materials higher and lower cure temperatures have been studied as well. The cure time is the recommended cure time for each of the materials. Table I also indicates possible application methods for these materials.

\section{Termination Materials}

Three different substrates were used; silver, tin and solder $(\mathrm{Sn} / \mathrm{Pb} 62 / 38)$. All substrates were cleaned with ethanol before use.

\section{Sample Preparation, ESR and Adhesive Strength Measurement}

The silver adhesive was applied by stencil printing in order to obtain a controlled thickness of approximately $150 \mu \mathrm{m}$ for all materials. All capacitors were placed manually and the adhesives were cured according to the required cure schedule.

ESR measurements were performed with a HP4284A LCR meter at the semi-finished E-case capacitors using kelvin clip gold plated test leads. The ESR measurements were performed at $1 \mathrm{VAC}, 100 \mathrm{kHz}$ by clamping one clip to the anode wire and the other to the termination substrate as shown in (1) Figure 1. A further analysis was done by evaluating the ESR number from the anode wire to the silver coating (2) and from the silver coating to the substrate (3). It was proven that a number of 15 capacitors from 1 single batch gives a reliable ESR number. Typical measurement of $70 \mathrm{~m} \Omega$ showed a standard deviation of approximately 3-4 $\mathrm{m} \Omega$.

The adhesive strength was measured using a die shear test of semi-finished B-case capacitors and recorded in Newton.

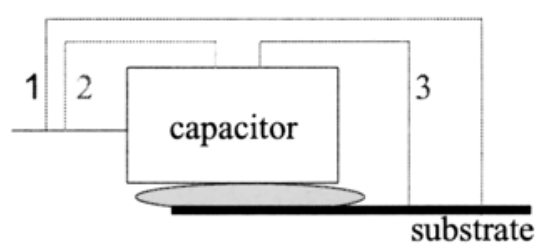

FIGURE 1 Schematic drawing of ESR measurements on a capacitor bonded on the substrate with a conductive adhesive. (1) form anode wire to substrate, (2) from anode wire to Ag coating, (3) from Ag coating to substrate. 


\section{RESULTS AND DISCUSSION}

The ESR performance as well as the mechanical strength of the electrically conductive adhesives has been evaluated. In a first paragraph the ESR level on different metallisations is discussed followed by the relation between ESR and volume resistivity and the effect of the cure schedule on ESR. In a second paragraph the shear strength on different substrates is studied. The influence of using different cure schedules is discussed and the failure mechanism is investigated in more detail. Finally some more details on the ESR contribution of the different interfaces are discussed.

\section{ESR Performance}

\section{(a) ESR on Different Substrates}

The ESR of the different silver adhesives on silver (Ag), tin ( $\mathrm{Sn}$ ) and solder ( $\mathrm{SnPb})$ substrates were evaluated. Adhesives $\mathrm{Al}$ and $\mathrm{A} 2$ were evaluated using 3 different cure profiles. All data are presented in Table II.

The lowest ESR numbers are obtained using silver terminations. All adhesives show ESR values between 63 and $75 \mathrm{~m} \Omega$, indicating that the ESR on a Ag substrate is not very dependant on the applied adhesive. The low ESR number obtained with the silicone adhesive A6 is remarkable but might be related to the pressure sensitive contact resistance of this material. When excluding this result, the ESR spread from different adhesives reduces to 69-75 $\mathrm{m} \Omega$. Further, the variation in ESR becomes smaller when similar cure temperatures are compared: at $180{ }^{\circ} \mathrm{C}$ from 72 to $75 \mathrm{~m} \Omega$; at $150{ }^{\circ} \mathrm{C}$ from 69 to $73 \mathrm{~m} \Omega$. This indicates that the ESR on a Ag substrate depends more on the cure schedule than on the Ag adhesive.

When using Sn substrates, pronounced differences in ESR performance between the various adhesives are observed. Best results are obtained with A7 and A2 showing values of $81 \Omega$ and 87 to $99 \Omega$. Moreover, ESR values are significantly higher as compared to the Ag substrate. Poor performing adhesives display a significant contribution to the ESR number of the semi-finished capacitor with ESR values ranging from 125 to $1000 \mathrm{~m} \Omega$ as observed for all other materials.

Clearly, when bonding on Sn-substrates, a proper selection of one of the above mentioned low ESR adhesives is necessary.

TABLE II Volume Resistivity and ESR Numbers on Different Substrates.

\begin{tabular}{|c|c|c|c|c|c|}
\hline \multirow[b]{2}{*}{ Material } & \multirow[b]{2}{*}{ Cure } & \multirow[b]{2}{*}{ Volume resistivity $(\Omega \mathrm{cm})$} & \multicolumn{3}{|c|}{$\operatorname{ESR}(m \Omega)$} \\
\hline & & & $A g$ & $S n$ & $\mathrm{SnPb}$ \\
\hline \multirow[t]{3}{*}{ A1 } & $60 \mathrm{~s} @ 180^{\circ} \mathrm{C}$ & $1.4 \times 10^{-4}$ & 75 & 125 & 132 \\
\hline & $30 \min @ 150^{\circ} \mathrm{C}$ & $7.2 \times 10^{-4}$ & 72 & 259 & 202 \\
\hline & $45 \min @ 120^{\circ} \mathrm{C}$ & 1.6 & 69 & 610 & 135 \\
\hline \multirow[t]{3}{*}{ A2 } & $60 \mathrm{~s} @ 180^{\circ} \mathrm{C}$ & $1.1 \times 10^{-4}$ & 75 & 89 & 74 \\
\hline & $30 \min @ 150{ }^{\circ} \mathrm{C}$ & $1.0 \times 10^{-4}$ & 71 & 87 & 89 \\
\hline & $45 \min @ 120{ }^{\circ} \mathrm{C}$ & $6.9 \times 10^{-3}$ & 72 & 99 & 84 \\
\hline A3 & $30 \min @ 150{ }^{\circ} \mathrm{C}$ & $2.8 \times 10^{-4}$ & 73 & 167 & 160 \\
\hline A4 & $1 \mathrm{~h} @ 150^{\circ} \mathrm{C}$ & $5.5 \times 10^{-4}$ & 70 & 164 & 81 \\
\hline A5 & $30 \min @ 150{ }^{\circ} \mathrm{C}$ & $1.2 \times 10^{-4}$ & 70 & 1082 & 157 \\
\hline A6 & $1 \mathrm{~h} @ 150^{\circ} \mathrm{C}$ & $3.2 \times 10^{-3}$ & 63 & 187 & 75 \\
\hline A7 & $1 \mathrm{~h} @ 180^{\circ} \mathrm{C}$ & $4.9 \times 10^{-5}$ & 72 & 81 & 83 \\
\hline
\end{tabular}


A similar conclusion can be made for the $\mathrm{SnPb}$ substrate although in general lower data are reported as compared to $\mathrm{Sn}$ substrates. Also for solder substrates a proper adhesive selection to achieve the best ESR performance will be necessary. Moreover, changes from solder to tin metallisations might have a significant impact on ESR data depending on the adhesive used.

\section{(b) ESR versus Volume Resistivity}

When comparing the ESR numbers with the volume resistivity of the conductive adhesives it becomes clear that there is no direct relationship. Materials with poor volume resistivity display good ESR numbers (e.g. material A1 on Ag after cure of $45 \mathrm{~min}$ at $120^{\circ} \mathrm{C}$ ) and vice versa (e.g. material A5 on Sn). This indicates that most probably it is not the bulk resistance of the adhesive but the poor contact resistance between the adhesive and the substrate that has the highest impact on the ESR. This issue will be further discussed in paragraph c.

\section{(c) ESR versus Cure Schedule}

The ESR numbers on the different substrates using different cure profiles for adhesives A1 and A2 indicate that significant differences in ESR level can be obtained. Clearly an optimisation of the cure schedule can give significant ESR improvement. Production speed and capacity is of course another major issue that influences the required cure schedule.

\section{Adhesive Strength of Conductive Adhesives}

Shear test results of the different silver adhesives on silver $(\mathrm{Ag})$, tin $(\mathrm{Sn})$ and solder $(\mathrm{SnPb})$ substrates were evaluated. All data are presented in Table III.

\section{(a) Shear Strength on Different Substrates}

For most adhesives, the adhesion on $\mathrm{Ag}$ is 20 to $50 \%$ higher than on $\mathrm{Sn}$ and $\mathrm{SnPb}$ substrates. In all cases material $\mathrm{A} 1$ gives the highest results. Adhesives A2, A3 and A8 give good results on $\mathrm{Sn}$ and $\mathrm{SnPb}$ as well. As expected, the silicone material $\mathrm{A} 7$ gives very low values. The adhesion of all epoxy based materials is acceptable and all epoxy materials perform very similar.

TABLE III Shear Strength (B-Case Capacitors) of Silver Adhesives on Different Substrates.

\begin{tabular}{|c|c|c|c|c|c|}
\hline \multirow[b]{2}{*}{ Material } & \multirow[b]{2}{*}{ Cure } & \multicolumn{3}{|c|}{ Capacitor shear strength (N) } & \multirow[b]{2}{*}{ Failure mechanism } \\
\hline & & $A g$ & $S n$ & $\mathrm{SnPb}$ & \\
\hline \multirow[t]{3}{*}{$\mathrm{Al}$} & $60 \mathrm{~s} @ 180^{\circ} \mathrm{C}$ & 16.7 & 10.1 & 9.6 & Capacitor failure \\
\hline & $30 \min @ 150{ }^{\circ} \mathrm{C}$ & 19.2 & 15.4 & 16.2 & Capacitor failure \\
\hline & $45 \min @ 120^{\circ} \mathrm{C}$ & 20.4 & 16.1 & 16.0 & Capacitor failure \\
\hline \multirow[t]{3}{*}{$\mathrm{A} 2$} & $60 \mathrm{~s} @ 180^{\circ} \mathrm{C}$ & 9.5 & 10.6 & 10.3 & Capacitor failure \\
\hline & $30 \min @ 150{ }^{\circ} \mathrm{C}$ & 14.6 & 12.1 & 11.9 & Capacitor failure \\
\hline & $45 \min @ 120^{\circ} \mathrm{C}$ & 15.2 & 11.6 & 9.8 & Capacitor failure \\
\hline A3 & $30 \min @ 150{ }^{\circ} \mathrm{C}$ & 9.8 & 13.6 & 13.7 & Capacitor failure \\
\hline A4 & $1 \mathrm{~h} @ 150{ }^{\circ} \mathrm{C}$ & 11.1 & 11.4 & 7.8 & Capacitor failure \\
\hline A5 & $30 \min @ 150{ }^{\circ} \mathrm{C}$ & 11.6 & 8.8 & 7.5 & Adhesive failure \\
\hline A6 & $1 \mathrm{~h} @ 150{ }^{\circ} \mathrm{C}$ & 2.7 & 2.0 & 2.2 & Adhesive failure \\
\hline A7 & $1 \mathrm{~h} @ 180^{\circ} \mathrm{C}$ & 15.01 & 12.0 & 9.9 & Capacitor failure \\
\hline
\end{tabular}




\section{(b) Shear Strength as Function of Cure Schedule}

Both materials A1 and A2 give better adhesion when cured at lower temperatures. At these lower temperatures the reaction is proceeding at a slower rate, which results in higher adhesion and probably also lower stress which will improve shear strength as well. Snap cure of the adhesives has a negative impact on the adhesion and such a snap cure process may require materials with improved adhesion.

\section{(c) Shear Strength and Failure Mechanism}

In 5 out of 7 cases the failure mechanism concerns a capacitor failure at the $\mathrm{MnO}_{2}$ /graphite interface. Only the epoxy silicone and silicone based materials show an adhesive failure. It is remarkable that despite the appearance of capacitor failures between the $\mathrm{MnO}_{2}$ and graphite layer (which is identical for all systems studied), differences in shear strength between the various adhesives are reported. A possible explanation for this phenomenon is that the shear strength of the capacitor depends on the stress relaxation mechanism of the adhesive.

\section{ESR Contribution of the Adhesives: Further Details}

Typical (low) ESR readings from the anode wire to the substrate range from 70 to $80 \mathrm{~m} \Omega$. In Table IV additional ESR data measured from the anode wire to the Ag-coating and from the Ag-coating to the substrate (as described in Fig. 1) are presented for adhesive A1.

In all cases the ESR number from the anode wire to the Ag-coating remains approximately constant at values between 74 and $80 \mathrm{~m} \Omega$. The ESR number from the coating to the silver substrate is in all cases lower than the anode wire/coating ESR number.

On the contrary $\mathrm{Sn}$ and $\mathrm{SnPb}$ metallisations show higher ESR readings from the coating to the substrate than from the anode wire to the coating. These higher ESR numbers on Sn and $\mathrm{SnPb}$ must be related with the contact resistance at the coating/adhesive/substrate interphase. Because the coating/adhesive composition and cure profile are similar in all cases, we can conclude that the high ESR values on $\mathrm{Sn}$ and $\mathrm{SnPb}$ are related with a poor contact resistance between the adhesive and the metal substrate.

TABLE IV ESR Numbers from (1) Wire to Substrate, (2) Wire to Coating and (3) Coating to Substrate Measured with Adhesive A1 on Different Substrates.

\begin{tabular}{llccc}
\hline & & $\begin{array}{c}\text { ESR }(m \Omega) \\
\text { wire/ } \\
\text { substrate }\end{array}$ & $\begin{array}{c}\text { ESR }(\mathrm{m} \Omega) \\
\text { wire/ } \\
\text { coating }\end{array}$ & $\begin{array}{c}\text { ESR }(\mathrm{m} \Omega) \\
\text { coating/ } \\
\text { substrate }\end{array}$ \\
\hline $\mathrm{Ag}$ & Cure & 75 & 79 & 42 \\
& $60 \mathrm{~s} @ 180^{\circ} \mathrm{C}$ & 72 & 76 & 41 \\
$\mathrm{Sn}$ & $30 \mathrm{~min} @ 150^{\circ} \mathrm{C}$ & 69 & 74 & 38 \\
& $45 \mathrm{~min} @ 120^{\circ} \mathrm{C}$ & 125 & 79 & 87 \\
$\mathrm{Sn} / \mathrm{Pb}$ & $60 \mathrm{~s} @ 180^{\circ} \mathrm{C}$ & 259 & 80 & 226 \\
& $30 \mathrm{~min} @ 150^{\circ} \mathrm{C}$ & 610 & 78 & 577 \\
& $45 \mathrm{~min} @ 120^{\circ} \mathrm{C}$ & 132 & 76 & 103 \\
& $60 \mathrm{~s} @ 180^{\circ} \mathrm{C}$ & 202 & 79 & 176 \\
& $30 \mathrm{~min} @ 150^{\circ} \mathrm{C}$ & 135 & 76 & 104 \\
\hline
\end{tabular}




\section{CONCLUSIONS}

The purpose of this study was to obtain a better understanding of all aspects influencing the equivalent series resistance (ESR) performance and processing of electrically conductive adhesives. Different adhesives were applied and the ESR and capacitor shear strength have been evaluated versus different processing parameters and metallisations used in the industry.

It was shown that there exists no relation between the volume resistivity of the studied adhesives and the ESR of the capacitors (similar conclusion as for the silver and graphite coatings). The lowest ESR values are obtained on Ag-plated leadframes and show only minor differences between different adhesives. $\mathrm{Sn}$ and $\mathrm{SnPb}$ substrates require an appropriate adhesive selection in order to achieve acceptable ESR numbers. Silicone and epoxy silicone adhesives might be useful when looking at ESR data but show very low mechanical strength which would result in high yield losses.

It can be concluded that when the appropriate adhesive is used, the ESR contribution of the adhesive is very small. Following selection criteria are most important to choose the best adhesive:

- Plating on the leadframe: $\mathrm{Ag}, \mathrm{Sn}$ or $\mathrm{SnPb}$

- Application method: dispensing, printing or pin transfer

- Cure conditions: oven cure (batch process) versus snap cure (in-line)

\section{References}

[1] Toomey, D. and Racine, J. (1995). Powerconversion and Intelligent Motion: The Fusion of Power and Motion Technology, 21(6).

[2] Hahn, R. and Melody, B. (2000). Passive components Industry, p. 17.

[3] Winkler, G., Gerbingler, J. and Brenner, M. (1999). Proceedings CARTS-EUROPE'99, p. 79.

[4] Ladd, J. (1999). Proceedings CARTS-EUROPE'99, p. 107.

[5] Prymak, J. D. (1999). Proceedings CARTS-EUROPE'99, p. 169.

[6] Zednicek, T. and Sita, Z. (1999). Proceedings CARTS-EUROPE'99, p. 54.

[7] Kobayashi, A., Saiki, Y. and Watanabe, K. (1998). Conference Proceedings Antec'98, p. 1202.

[8] Dreezen, G., Deckx, E., Cheng, S. and Luyckx, G. (2000). Proceedings CARTS-Europe 2000, p. 37.

[9] Stroud, J. P. (1990). Proceedings 40th Electronic Components and Technology Conference, Vol. 2, p. 1009.

[10] Gill, J. AVX Technical Publication, http://www.avxcorp.com/ 

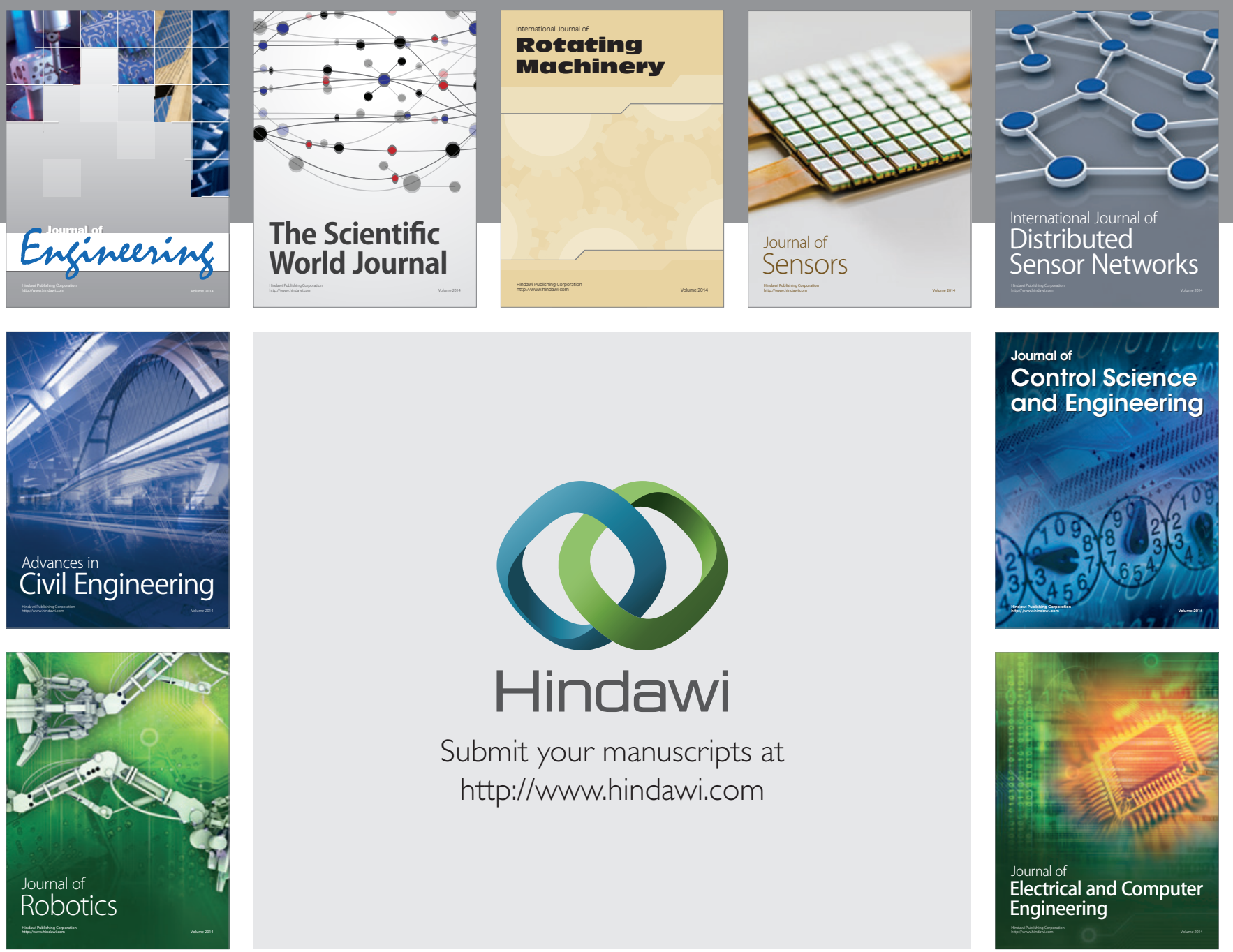

Submit your manuscripts at

http://www.hindawi.com
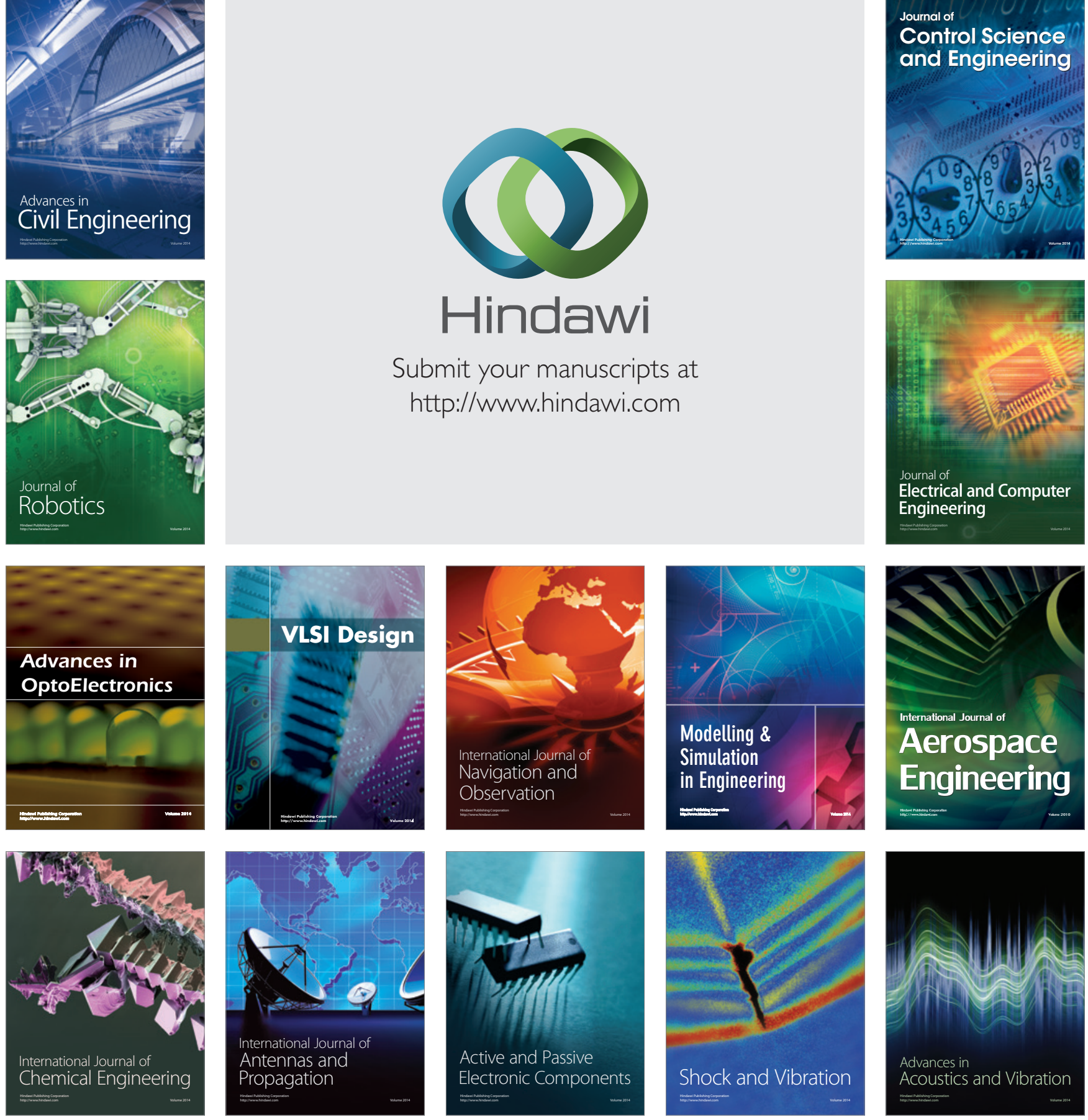